\title{
Empowering Women Leaders for Work-Integrated e-Learning: Social Changes and Persistent Challenges
}

\author{
https://doi.org/10.3991/ijac.v13i4.14749 \\ Amy Wong \\ Singapore University of Social Sciences, Clementi Road, Singapore \\ Karin Sixl-Daniell (四) \\ Manipal GlobalNxt University, Kuala Lampur, Malaysia \\ karin.sixleglobalnxt.edu.my
}

\begin{abstract}
Information technology is increasingly being adopted within various sectors, especially in education. This study examines the effects of a work-integrated e-learning program for women leaders offered by a fully online institution. Data was collected from 61 respondents via an online discussion board forum. The findings showed that integration of technology-enhanced learning into the workplace for purposes of training and development can bring about a variety of social changes at the individual, group, and organizational levels. The findings highlight important insights for the design and delivery of fully online training and development programs that can bring about social change, taking into consideration the persistent challenges faced by women leaders. Further discussion and implications are provided.
\end{abstract}

Keywords—e-learning, work-integrated learning, social change, women leadership

\section{Introduction}

Over the past decades, the number of women assuming corporate leadership roles has risen in most parts of the world. Women play ever more important roles across organizations, both private and public. However, in 2019, women held only 5 percent of CEO positions of the S\&P 500 companies while the number of total female employees in those companies stood at 44.1 percent [1]. At the board level, 21 percent of seats were held by women, while at the executive and senior level, the percentage was 26.5 percent, with 36.9 percent at the entry to mid-level. Although the percentage of women leaders is on the rise, there is room for improvement as women are still largely underrepresented in senior leadership positions [2], [3], [4], [5]. One of the reasons for this is due to a lack of training and development opportunities for women globally [6], [7].

Workplace-based training and development programs are necessary to help individuals enhance their skills and knowledge, adapt to societal change and advance their careers. One way to approach this need for women is to offer work-integrated e- 
learning training such as women leadership programs, designed to equip women with leadership and business development skills [8], [9], [10]. These programs can help women progress into senior management and board positions by focusing on the development of self-awareness as well as leadership skills, building strong networks, undertaking challenging assignments, improving self-confidence, and acquiring worklife balance skills [11], [12]. Further, research has shown that women who participate in company-initiated training and development activities are less likely to leave their jobs [13].

Despite the numerous benefits of women-centric training and development programs, to date, there is still a lack of such initiatives being implemented by companies, both large and small, on a global scale. Some reasons could be due to the high perceived costs (i.e., monetary, time and effort), general perceived resistance, implementation challenges, and uncertainty in results (i.e., social changes, work productivity, job performance). To further understand the outcomes of women-centric training programs, this study aims to examine the effects of a work-integrated elearning program for women leaders offered by a fully online institution. Using a mixed method approach, program outcomes such as social changes, challenges encountered, as well as training effectiveness are explored. The remainder of the paper is organized as follows. First, a review of the literature is discussed, while the method of the study is presented. Next, the results, discussion and implications are provided, followed by limitations and future research.

\section{$2 \quad$ Literature Review}

\subsection{Women leaders}

Several studies have recognized the value that women bring to realizing new business opportunities in the workplace. For example, European companies with more gender diversity reported higher than average stock performance [14], companies with strong financial positions have the highest number of women in leadership roles [15], while companies with increased gender diversity are more profitable [16]. Further, women scored higher than men in most leadership skills [17] and are less likely to compromise ethics in leadership positions compared to their male counterparts, leading to ethically sounder decisions in a corporate environment [18].

A KPMG study emphasized the need for the provision of corporate training and development opportunities for women leaders [19]. The study highlighted the importance of empowering women to reach higher ranks and recommended several key focal areas, namely socializing leadership in the early career stage, modelling leadership, providing networking opportunities and building confidence through role models. In addition, corporations should identify and develop high-performing women, actively provide qualified women with leadership opportunities, and put in place aspirational career paths for women at work by providing corporate training and development programs to help women advance forward. These findings are further reinforced in several studies [20], [21]. 
However, faced with the burden of childcare and the numerous family duties, women may be hampered in their attempts to pursue traditional face-to-face training and development programs required for career enhancement. The advent of technologyenhanced learning has paved the way for access to online training and development opportunities [22]. To help more women advance to senior positions, such technologyenhanced learning programs can be implemented as part of corporate and workplace training. Organizations can utilize e-learning to retain their pool of women talent, while at the same time understanding and honoring the multiple work-life commitments that women face throughout their careers, such as caring for young children and elderly family members. Importantly, women should have full access to training and development opportunities throughout their careers, not limited solely to specific times in their careers [23]. This can bring about talent retention, build high performance, as well as empowered and effective networks with the goal of generating opportunities for women's leadership growth, bringing about impactful social changes.

\subsection{Work-integrated e-learning}

Along with the advancement of information technology, universities have been under increasing pressure to adopt e-learning as part of teaching and learning. To capitalize on this emerging trend, higher education institutions can create e-learning opportunities that are customized to specific industry contexts and workplace needs. When used in the workplace, e-learning allows for versatility, flexibility, time, space and scope efficiencies, and provides opportunities for diversity and inclusion [24]. Work-integrated e-learning integrates the requirements of educational programs with workplace expectations, through the use of different technologies within a platform to create convenience for the learners [25]. By incorporating work-integrated e-learning into university program curricula, learners can be equipped with the workplace skills and knowledge contextualized by the rapid growth of technology. This technologyenhanced learning allows for the holistic transformation of education and leads to increased learner motivation, autonomy, enthusiasm, and job readiness [26]. In times of societal challenges due to sudden and unexpected events such as the COVID-19 pandemic, remote learning, in particular work-integrated e-learning, can be used to prevent the spread of virus outbreak and overcome the constraints that other means of training might present.

\subsection{The learning management system}

A commonly used system, the Learning Management System (LMS), is often adopted as the main platform for the delivery of work-integrated e-learning due to its data reliability, privacy and continuity [27]. An LMS can provide students from different backgrounds and lifestyles with the opportunity to study, being devoid of time and space limitations, within a secure online environment [28]. Within an LMS, there are several communication and collaboration tools that can be used to construct knowledge, solve problems, build a community of learners, and support higher order learning objectives and critical thinking through discussions and ongoing 
conversations. A well-designed LMS can enhance learners' social experiences, help them build familiarity with other learners, as well as connect them with like-minded learners with similar interests.

Although several universities have jumped onto the e-learning bandwagon, many of the e-learning courses in the market are cumbersome, with technical and design problems that continue to negatively impact students' learning process. Most of the standard LMS incorporated functionalities such as grade book, discussion boards, emails, as well as social media elements such as blogs and wikis. Yet, collaborative tools such as online social media platforms, made popular with the rapid changes in technology, have not been embedded effectively within the LMS [29]. There is also an ongoing debate as to whether the embedded collaboration tools are efficient. As stated in [30], social media tools (i.e., WhatsApp, Skype) are more user-friendly and easily accessible, as such tools provide a better interactive space than other collaborative applications embedded within LMSs. On the other hand, software providers have been launching extra features in their applications to facilitate the ease of online collaboration (i.e., Microsoft Teams, Skype for Business, Adobe Connect, Zoom). Hence, there is a need to examine the design and delivery of work-integrated e-learning programs that can deliver the benefits of e-learning to learners in an effective manner.

\section{$3 \quad$ Method}

\subsection{Research sample}

The participants of the study included 61 female executives and managers from a global multinational information technology service and consulting company with over 110,000 employees in 73 countries. The participants are aged between 25 and 30 years old ( 20 percent), 30 and 35 years old ( 32 percent), 35 and 40 years old ( 24 percent), with another 8 percent aged between 40 and 45 years old. In terms of working experience, 23.8 percent worked for less than five years, 38.1 percent worked between 5 and 10 years, 28.6 percent worked between 11 and 15 years, and 9.5 percent worked between 16 and 20 years.

The participants were enrolled in a Women Leadership Executive Program delivered by a fully online institution and hosted on an in-house developed LMS. Throughout the highly customized six-month program, which includes a mixture of online content, faculty recorded videos, animation, reflection activities, and self-assessment quizzes, participants read the online content, watched the videos online, and attended the fortnightly 90-minute synchronous webinars and contributed to the weekly asynchronous discussion boards. At the end of the program, the participants were asked to submit a team project on how the key learnings from the program can be implemented at the workplace to bring about changes that can benefit women employees in the organization. 


\subsection{Research context}

Six broad modules were covered in the online courseware, namely People Leadership, Strategic Management for Innovative Business, Entrepreneurial Thinking, Ethical Decision Making, Financial Essentials and Managing Change. The modules were selected and developed based on the needs of the organization. Each module, facilitated by a female faculty and subject matter expert, lasted one month. All the faculty members have doctoral degrees and have been teaching with the online institution for more than 12 years. The countries of residence of the faculty include Austria, Australia, India, Singapore and the United States of America.

Using the asynchronous discussion board tool, the participants were able to collaborate and communicate with each other to construct knowledge. Further, participants were asked to share their views in the formal discussion boards and reflect on their key takeaways on a fortnightly basis. This provides them with the opportunity to compare themselves with the faculty experts and other learners with varying stages of work experience. In addition, participants needed to work on a team assignment at the end of the course. To encourage informal networking and interaction, the participants used social media tools such as the class WhatsApp chat and Skype to connect with peers and the faculty members.

\subsection{Data collection}

The research was undertaken using both qualitative and quantitative methods, where the quantitative research (i.e., survey) was used to further verify the qualitative data (i.e., content analysis of online discussions). To ensure confidentiality and anonymity of the participants, the data was analyzed through data extraction from the backend.

The qualitative data for this study was taken from two separate discussion boards which commenced in the first month and fourth month of the program respectively. The first discussion board required participants to share their views on their role as a female leader in their organization, and how they fit into the role. Participants were also asked to share their perceptions of the key aspects of future female leaders and the role and impact of cultural interaction and social networks in women's leadership. For the second discussion board, participants were asked to share the challenges they encountered in their career and how they overcome the challenges. Participants were also asked to share their perceptions of their colleagues' attitudes and behaviors as a result of the changes they implemented to overcome the challenges, and how these affect their future decision-making process as a female leader.

To allow for data triangulation, a survey was administered at the end of the program. The survey consisted of three questions related to module design (i.e., structure, organization, discussion board), four questions related to module content (i.e., engaging, relevant, critical thinking, relevance to workplace and role), and four questions related to module facilitation (i.e., knowledgeable, helpful and approachable faculty, support from staff, and use of webinars and discussion boards). Two open ended questions were included, one on feedback and suggestions for improvement, the other on the application of learning to the workplace and role. 


\section{$4 \quad$ Findings}

A total of 93 main posts and 243 follow-up posts were made for the first discussion board on the role of female leaders. For the second discussion board on challenges in their roles as female leaders, a total of 66 main posts and 203 follow-up postings were made. A qualitative content analysis approach is used to analyze the main postings as well as follow-up discussions and interactions within the discussion board. First, the authors separately categorized the data into themes that are related to the theoretical definitions and aspects of the factors. On agreement of the main categories, the authors then separately analyzed, classified and interpreted the frequency of the results using quantitative steps of analysis. Throughout the content analysis process, the authors cross-checked for formative (i.e., confirmation of main categories) and summative (i.e., verification of consistency of classified data) reliability [31]. The classification of the categories and data was consistent between the two authors and an inter-rater reliability of 100\% was achieved. The findings are presented in Tables 1 and 2, and the analysis of the data was conducted according to the categories below.

\subsection{Social changes}

In order to examine the impact of work-integrated e-learning on social changes, participants were asked to share their views on the Women Leadership Executive Program and how their key reflections and take-aways brought about social change and impact in their workplaces. The categories highlighted in the discussion boards are presented in Table 1 according to the individual, group, and organizational levels. In general, the participants agreed that they need to mindfully incorporate the learnings and suggestions shared and make gradual efforts towards implementing social change.

Table 1. Social Changes

\begin{tabular}{|c|}
\hline Individual level \\
\hline Keeping abreast of changes in the society and readiness to embrace change \\
\hline Awareness of the role and perils of social changes (i.e., use of social media) \\
\hline Practice equality, treat everyone the same, leadership as an exchange of ideas \\
\hline Apply management skills (i.e., people, diplomatic) to achieve goals \\
\hline Group level \\
\hline $\begin{array}{c}\text { Build, motivate and grow cohesive teams (i.e., from 'I' to 'We'), work towards a } \\
\text { conducive workplace }\end{array}$ \\
\hline $\begin{array}{c}\text { Social change movements (i.e., \#Me Too) and move away from stereotypes, } \\
\text { prejudices and stigma }\end{array}$ \\
\hline Hold regular meetings to solve issues and address concerns at the workplace \\
\hline Approach workplace challenges with trial and error \\
\hline $\begin{array}{c}\text { Organizational level } \\
\text { Create women-empowered workplaces, empower other women to take risks, help } \\
\text { other women grow }\end{array}$ \\
\hline
\end{tabular}


Adaptation to potential changes, including ethics, behaviors and communication styles

Compassion culture at the workplace, sensitive and empathetic to cultural differences, religious beliefs and sexual orientations

With globalization and increased migration, cross-cultural skills are necessary to impact change

Embrace innovation and technology, necessity to work in virtual teams, which requires the building of trust and working relationships with people one has never met

To provide a better visualization of the data, a word cloud of the social changes is presented in Figure 1.
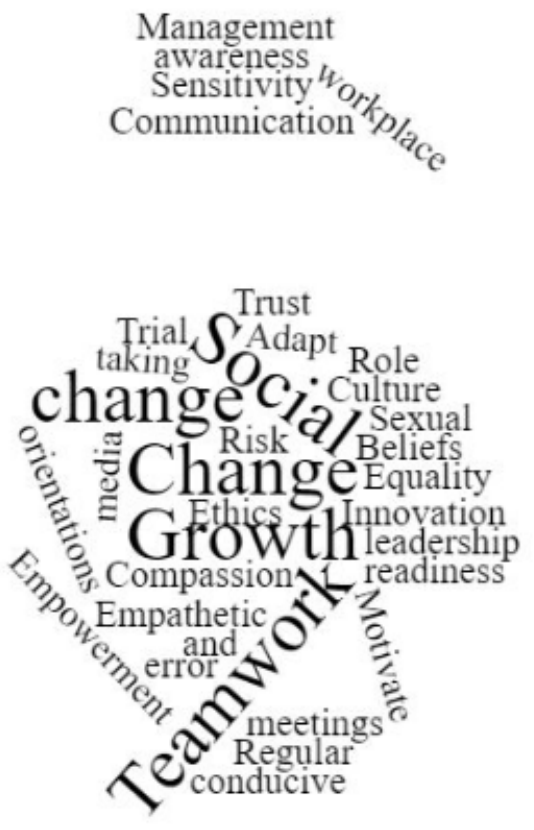

Fig. 1. Word cloud of social changes

\subsection{Persistent challenges}

In addition, participants were asked to share the persistent challenges they faced at their workplace, and whether aspects of the program helped them overcome these challenges. The categories mentioned in the discussion board are presented in Table 2. In addition to the generic work-related and change-related challenges, female leaders 
are more susceptible to persistent challenges such as gender bias (i.e., unfair treatment, appraisals) and gender inequality (i.e., glass ceiling, income and workload inequality).

Table 2. Challenges encountered

\begin{tabular}{|l|}
\hline \multicolumn{1}{|c|}{ Gender-related } \\
\hline Glass ceiling and inequality in workload and income \\
\hline Gender bias, being a female leader in a male-centric business world \\
\hline Being accused openly in an unfair manner by a male manager \\
\hline Unfair team appraisals \\
\hline Overall work-life balance Change-related \\
\hline Continuous learning and unlearning due to changing of mindsets \\
\hline Adaptability to change \\
\hline People who find it difficult to accept changes \\
\hline Politics at work \\
\hline Conflict management \\
\hline Cultural differences at client work environment \\
\hline
\end{tabular}

To provide a better visualization of the data, a word cloud of the challenges encountered is presented in Figure 2.

\section{Stereotypes \\ Unfair}

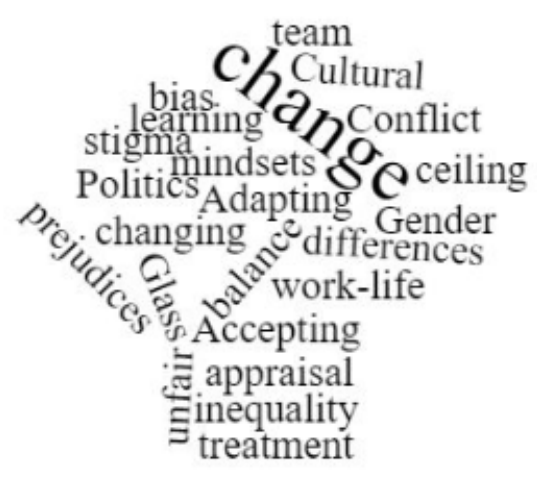

Fig. 2. Word cloud of challenges encountered 


\subsection{Effectiveness of work-integrated e-learning}

To measure the effectiveness of the workplace-based e-learning program, an end of course survey was administered. Most of the participants enjoyed the interactive synchronous webinar sessions, with 92.7 percent of the participants stating that the use of webinar as an e-learning tool was particularly helpful in delivering the learning. A majority of the participants (95.1 percent) found that the aims of the module were clearly articulated, 92.7 percent found the modules well-structured and organized, while 95.1 percent of the participants felt that the program content enabled them to think critically about workplace issues. Most of the participants felt that the program content was engaging (90.3 percent) while 92.7 percent of the respondents reported that the female faculty members interacted well with them in the discussion boards, sharing relevant insights and inspiring stories of female leaders that motivated and encouraged the learners.

Participants were also asked to provide feedback on the applicability of the learning to their workplace and the transferability of the learning to their current role in the organization. The majority of the participants (92.7 percent) felt that the workintegrated e-learning allowed them to apply the theories, concepts, and frameworks learned to their workplace and their roles. In this aspect, some participants felt that the program helped them increase self-awareness and confidence, implement good decision making, resolve work conflicts, strengthen people management skills and apply appropriate leadership styles to different work situations. More importantly, the participants learned about risk taking, capitalizing on work opportunities, speaking up, balancing work-life priorities and achieving their set-goals in both aspects of professional and personal life.

An analysis of the open-ended comments in the survey showed that, despite having fortnightly webinars, the participants would like to have more sessions so that they can clarify concepts covered in the module and engage in more interactions with the faculty members. When asked for suggestions for improvements, the participants would like to have more female industry speakers and experts share their views on the topics covered in the program as well as the use of further case studies, real-life inspirational stories and interviews of successful women leaders, which can help them in modelling leadership success.

\section{$5 \quad$ Discussion and Implications}

\subsection{Social changes}

The participants mentioned that the various readings and videos of inspirational and motivating female leaders embedded within the online content helped open their perspectives to workplace challenges. In terms of technological tools, the use of the discussion board tools, both in a formal (i.e., assessed) as well as informal (i.e., nonassessed) manner instilled a collaborative and participative spirit which further bonded the learners together. The sharing sessions of actual workplace situations in the informal 
WhatsApp chat helped participants understand workplace issues faced by their female colleagues in other roles, departments, business units, and geographic locations. This heightened the participants' sensitivity and adaptability to cultural and social differences, leading to workplace agility, receptivity towards continuous improvement, and a learning mentality.

In addition, through the fortnightly synchronous webinar series, faculty members made it a point to share best practices and remind participants of the importance of work-centered behaviors for female managers. These range from the ability to multitask, manage time, prioritize family commitments, being organized and planning in advance, and being able to trust others and delegate tasks to empower and encourage other colleagues. The ongoing interactions among the participants and between the participants and their female professors over the six-month program provided the learners with strong moral support and gave them the strength and courage to step out of their comfort zones, to create social changes that impact their workplaces. These socializing opportunities provided the participants with networking opportunities which helped them build their confidence through role models [32].

\subsection{Persistent challenges}

While several challenges have been highlighted by the participants, many solutions were suggested and strategies were proposed within the online community of learners, both in the discussion boards and in the WhatsApp chat. A minority of these persistent challenges could be resolved during the course of the program through adopting a positive mindset, perseverance, and believing in oneself. Some excerpts from the discussion boards are as follows:

- "Few definitely had issues with adjusting or accepting the change of reporting, alignment with a new team member or someone who is younger to them - but with time things changed and so did the behavior, which turned out to be a positive outcome."

- "Whenever we take up any challenging assignment, people try to influence us, judge our capabilities and some even try to create doubts in our minds whether we will be able to accomplish it or not. The key lies in staying true to our beliefs and remaining confident."

Moreover, most of the participants appreciated the opportunity to undertake the Women Leadership Executive Program, as they were able to seek solace, vent frustrations and garner encouragement from peers, gaining the strength and support they needed after a hard day of work, within a safe women-centric environment.

\subsection{Application of work-integrated e-learning}

Most of the participants shared that they were able to apply the learnings to their workplace almost immediately, given that the learning content was specially curated 
and highly customized to the learners' industry context and workplace needs. Some excerpts include the following:

- "After learning about workplace ethics in this module and through the online webinar, I am able to apply the decision-making approaches I learnt, especially the topic on uncertainty, which was really very helpful for me because I think sometimes, I might have overlooked the uncertainty of risk taking while making a decision."

- "Based on my learning in this module, in my future decision-making processes, I will use ethical decision-making aids and will assess the risks better than before. I can make better decisions now, with an understanding of the possible challenges and how can they be overcome."

Decision-making processes and their outcomes were likely to be improved as learners benefitted from the approaches and tools taught in the program, which were highly applicable to their work environment. Moreover, the participants reported increased self-awareness as well as increased self-esteem, which can bring about positive changes to their work environment and personal environment, including their greater social circle. This further reinforced the benefits that work-integrated e-learning can deliver, including versatility, flexibility, time, space and scope efficiencies as well as diversity and inclusion [33].

\subsection{New directions and initiatives}

Prior to the end of the Women Leadership Executive Program, the participants voluntarily shared their contacts, formed network and support groups, and initiated future projects, some of which were ideas taken from the final project in the program. This reinforced the findings in a study on communication pattern and women leadership success, which found that successful women rely on a wide network (i.e., peers, coworkers) for input about work, life, and relationships, as well as for identifying career opportunities with a good work-life balance [34]. To this end, some participants started a self-help group as a small step towards helping women in their workplace. Other initiatives include projects to enable women to continue to work part time while caring for their families, helping female employees and their families start small businesses (i.e., becoming home chefs and supplying food to the workplace on demand), as well as proposals to retain female employees in the workplace and to kickstart their second careers.

\subsection{Implications for e-learning providers}

The findings provide useful insights for higher education institutions who are interested in offering customized workplace-based e-learning programs as part of executive education. With work-integrated e-learning, learners can be equipped with the workplace skills and knowledge contextualized by the rapid growth of technology. In terms of the design and delivery of fully online executive programs that can bring 
about social change, a mixture of communication and collaboration tools can be used within a well-designed LMS to construct knowledge, solve problems, build a community of learners, support higher order learning objectives and critical thinking through discussions and conversations.

A safe learning environment, where employees participate in the use of technological tools such as online discussion boards, synchronous webinars, WhatsApp chat, Zoom, Microsoft Teams, Collaborate, Skype, and other tools can remove existing barriers (i.e., time and space) as well as potential barriers in mixed groups due to social and cultural differences. In addition, the richness of the e-learning environment can be extended to the workplace through the use of social media platforms that are commonly used by learners. Such platforms can be embedded into the LMS to provide learners with an interactive and easily accessible space for both formal and informal learning. Further, the data driven learning analytics tool, a common feature in most LMSs, can be utilized to further examine the effectiveness of e-learning programs.

Given the increased adoption of remote working and the gradual acceptance of online training and development programs during the COVID-19 outbreak, training organizations, institutions, and LMS providers should capitalize on this opportunity to implement technology-enhanced learning programs as part of an emergency preparedness initiative for business continuity. The (necessitated) readiness for sudden, radical and unprecedented change in most parts of the population can be facilitated effectively when e-learning is well-integrated into people's daily lives, both at work and within their social communities.

\section{Conclusion and Future Research}

This study examined the use of work-integrated e-learning in the training and development of female managers and leaders in a global multinational information technology service and consulting company. The integration of technology-enhanced learning into the workplace for purposes of training and development can bring about a variety of social changes at the individual, group, and organizational levels.

In terms of limitation, this study can benefit from additional qualitative interviews and focus groups in order to gather in-depth understanding regarding the use of workintegrated e-learning. Future research should investigate the impact of technology on learning cultures (i.e., both formal and informal) in workplaces situated in different industries and economies (i.e., developing and developed). Finally, a longitudinal study should be undertaken to ascertain how e-learning programs and new technology disruptions can facilitate social and cultural changes within the workplace and which disruption elements can contribute to professional development and career progression for female leaders of the future.

\section{$7 \quad$ References} [1] Catalyst (2019): Pyramid: Women in S\&P500 Companies
https://www.catalyst.org/research/women-in-sp-500-companies/ 
[2] Biletta I, Mullan, J. Parent - Thirion, A., Wilkens M. (2018): Women in management: underrepresented and overstretched https://www.researchgate.net/publication/328027092 Women in management underrepr esented and overstretched

[3] Huang, J., Krivkovich, A., Starikova, I., Yee, L. and Zanoschi, D. (2019). Women in the Workplace 2019. McKinsey \& Company, October. https://www.mckinsey.com/featuredinsights/gender-equality/women-in-the-workplace-2019

[4] Seo G., Huang W., Han S. (2017) Conceptual Review of Underrepresentation of Women In Senior Leadership Positions From A Perspective of Gendered Social Status In The Workplace: Implication for HRD Research and Practice. https://doi.org/10.1177 $\underline{1534484317690063}$

[5] Warner, J., Ellmann, N. and Boesch, D. (2018). The Women's Leadership Gap. Center for American

Progress, https://www.americanprogress.org/issues/women/reports/2018/11/20/461273/womensleadership-gap-2/

[6] Davis, P. J. (2012): The global training deficit: The scarcity of formal and informal professional development opportunities for women entrepreneurs. Industrial and Commercial Training, 44(1), 2012, pp. 19-25. https://doi.org/10.1108/00197851211193381

[7] Luu, T.N., \& Shao, Y. H. (2019). The Impact of Training on Turnover Intention: The Role of Growth Need Strength among Vietnamese Female Employees. South East Asian Journal of Management, 13(1), 1-17. DOI: https://doi.org/10.21002/seam.v13i1.9996

[9] Biletta I.; Parent-Thirion A. (2019): Women in management: If we want to get serious about gender equality we need to talk about job quality https://www.researchgate.net/publication/331590004_Women_in_management_If_we_wa nt to get serious about gender equality we need to talk about job quality

[10] Hill, C., Miller, K., and Benson, K. (2016). Barriers and Bias. The status of women in leadership. American Association of University Women, USA. https://files.eric.ed.gov /fulltext/ED585546.pdf

[11] Schmidt, C., Longobardi, F., Wyne, J., \& Lavine, R. (2019). To Retain Rising Women, Invest in Relationships. Public Accounting Report, 43(5), 12.

[12] O'Neil, D.A. \& Bilimoria, D. (2005): Women's career development phases: idealism, endurance, and reinvention. Career Development International, 10(3), 2005, pp. 168-89. https://www.researchgate.net/publication/235267738 Women's career development phas es_Idealism endurance and reinvention/link/577c0fac08aec3b743366e84/download

[13] Weyer, B. (2007): Twenty years later: explaining the persistence of the glass ceiling for women leaders. Women in Management Review, 22(6), 2007, pp. 482-96. https://doi.org/10.1108/09649420710778718

[14] Luu, T. N., \& Shao, Y. H. (2019). The Impact of Training on Turnover Intention: The Role of Growth Need Strength among Vietnamese Female Employees. South East Asian Journal of Management, 13(1), 1-17. DOI:10.21002/seam.v13i1.9996

[15] Desvaux, G., Devillard-Hoellinger, S. and Meaney, M.C. (2008): A business case for women. The McKinsey Quarterly, September 2008.

[16] Sinar, E., Wellins, R. S., Ray, R. Lui, A., Neal, S. (2015): Ready-Now Leaders: Meeting Tomorrow's Business Challenges. Global Leadership Forecast, DDI. http://www.ddiworld.com/DDI/media/trend-research/global-leadership-forecast-20142015 tr_ddi.pdf?ext=.pdf

[17] Noland, M., Moran, T., Kotschwar, B. (2016): Is Gender Diversity Profitable? Evidence from a Global Survey. Peterson Institute for International Economics. Accessed 18 March 
2020, https://www.piie.com/publications/working-papers/gender-diversity-profitableevidence-global-survey

[18] Zenger, J., Folkman, J. (2019): Research: Women core higher than men in most leadership skills, Harvard Business Review, https://hbr.org/2019/06/research-women-score-higherthan-men-in-most-leadership-skills

[19] Kennedy, J. and Kray, L. (2012): "Who is Willing to Sacrifice Sacred Values for Money and Social Status? Gender Differences in Reactions to Taboo Trade-offs." IRLE Working Paper No. 124-12. 2012. http://irle.berkeley.edu/workingpapers/124-12.pdf

[20] Veihmeyer, J., and Doughtie, L. (2015). Moving Women Forward into Leadership Roles. KPMG.https://home.kpmg/content/dam/kpmg/ph/pdf/ThoughtLeadershipPublications/KP MGWomensLeadershipStudy.pdf

[21] Huang, J., Krivkovich, A., Starikova, I., Yee, L. and Zanoschi, D. (2019). Women in the Workplace 2019. McKinsey \& Company, October. https://www.mckinsey.com/featuredinsights/gender-equality/women-in-the-workplace-2019

[22] Wippermann, C. (2010). Women in Executive Positions. German Federal Ministry for Family Affairs, Senior Citizens, Women, and Youth, https://www.bmfsfj.de/blob /93878/24ef73d6200f47c4b5c25702af30bec4/frauen-in-fuehrungspositionen-englischdata.pdf

[23] Klassan, A. (2019). Deconstructing Paper-Lined Cubicles: Digital Literacy and Information Technology Resources in the Workplace, International Journal of Advanced Corporate Learning, $\quad 12, \quad 3, \quad$ pp. 5-12. $\quad$ https://online-journals.org/index.php/ijac/article/view/11170/6163

[24] Knight, J. (2012). Top women leaders. Training Journal, pp. 54-58. https://www.trainingjournal.com/articles/feature/top-women-leaders

[25] Londt, C., \& Moldenhauer, L. (2018). Best Practice Focused Occupationally-Directed Education, Training and Development Practice Prospects Linked to Workplace E-Learning. International Journal of Advanced Corporate Learning, 11 (2), 4-10. https://doi.org/10.3991/ijac.v11i2.9140

[26] Barker, A., Krull, G. and Mallinson (2005). A Proposed Theoretical Model for M-Learning Adoption in Developing Countries. Proceedings of m-Learn Conference. https://pdfs.semanticscholar.org/7766/1f9fcc6291271be7728a886e\%20e62c3409a7ec.pdf

[27] Londt, C., \& Moldenhauer, L. (2018). Best Practice Focused Occupationally-Directed Education, Training and Development Practice Prospects Linked to Workplace E-Learning. International Journal of Advanced Corporate Learning, 11 (2), 4-10. https://doi.org/10.3991 ijac.v11i2.9140

[28] Zanjani, N., Nykvist, S. S., and Geva, S. (2012). Do students and lecturers actively use collaboration tools in learning management systems? In Biswas, G., Wong, L.-H., Hirashima, T., and Chen, W. Eds., Proceedings of 20th International Conference on Computers in Education, ICCE 2012, pp.698-705. National Institute of Education, Nanyang Technological University, Singapore

[29] Heirdsfield, Walker, S., Tambyah, M., and Beutel, D. (2011). Blackboard as an online learning environment: What do teacher education students and staff think? Australian Journal of Teacher Education, 36, 7, pp.1-16. https://ro.ecu.edu.au/cgi/viewcontent.cgi?article=1603\&context=ajte

[30] Stern, D. M., and Willits, M. D. 2011. Social media killed the LMS: Re-imagining the traditional learning management system in the age of blogs and online social networks. Cutting-edge Technologies in Higher Education, 1, pp.347-373. https://doi.org/10.1108/S2044-9968(2011)0000001020 
[31] Dabbagh, N. and Kitsantas, A. (2012). Personal Learning Environments, social media, and self-regulated learning: A natural formula for connecting formal and informal learning. The Internet and Higher Education, 15, 1, pp. 3-8. https://doi.org/10.1016/j.iheduc.2011.06.002

[32] Mayring, P. (2015). Qualitative Inhaltsanalyse. BELTZ.

[33] Veihmeyer, J., and Doughtie, L. (2015). Moving Women Forward into Leadership Roles. KPMG.https://home.kpmg/content/dam/kpmg/ph/pdf/ThoughtLeadershipPublications/KP MGWomensLeadershipStudy.pdf

[34] Londt, C., \& Moldenhauer, L. (2018). Best Practice Focused Occupationally-Directed Education, Training and Development Practice Prospects Linked to Workplace E-Learning. International Journal of Advanced Corporate Learning, 11 (2), 4-10. https://doi.org/10.3991 /ijac.v11i2.9140

[35] .Yang Y, Chawla, N. V., and Uzzi, B. (2019). A network's gender composition and communication pattern predict women's leadership success, Proceedings of the National Academy of Sciences of the United States of America, pp. 2033-2038. https://doi.org/10.1073 /pnas. 1721438116

\section{Authors}

Amy Wong is Senior Lecturer at the Singapore University of Social Sciences, 463 Clementi Road, Singapore 599494. She holds a Ph.D. in Management from Monash University, Australia, and has published in journals such as Journal of Services Marketing, Journal of Consumer Behaviour, and Journal of International Consumer Marketing.

Karin Sixl-Daniell is Professor at Manipal GlobalNxt University, Jalan Tun Sambanthan, 50470 Kuala Lumpur, Malaysia. She holds a Ph.D. in Social and Economic Sciences from the University of Graz, Austria, and is also associate faculty at universities in Austria, Canada, Germany, Hungary and Singapore.

Article submitted 2020-04-09. Resubmitted 2020-07-08. Final acceptance 2020-07-21. Final version published as submitted by the authors. 